\title{
Research on the Current Situation and Countermeasures of Medical Ethics Education for Medical Major Students in Higher Vocational Colleges
}

\author{
Hongcai Li, Hong Xu, Fuqing Liu, Fangqing Bai \\ Department of Medicine, Binzhou Polytechnic College, Binzhou, 256600, Shandong, China \\ Email: 252418973@qq.com
}

Keywords: Higher Vocational College; Medical Specialty; Medical Ethics Education; Present Situation; Countermeasures

\begin{abstract}
With the rapid development of economy and society and the change of medical model, medical science is developing with each passing day, and people's demands for physical health are also getting higher and higher. So in the new period, there are new requirements for the training goal of medical students. Medical education requires students not only to have sufficient medical knowledge and medical skills, but also to have good quality of medical ethics. The investigation shows that medical colleges and universities at this stage have made great efforts in educating students' medical professional knowledge, but there are many deficiencies in the education of students' medical ethics, which leads to the lack of practical effect of medical ethics education in schools. Whether it's for the student's future or for the school, the exhibition has a very negative impact. This paper mainly analyzes the current situation of medical ethics education for medical students in higher vocational colleges and puts forward some solutions.
\end{abstract}

\section{Introduction}

The objectives of vocational education include knowledge goals, capability goals and quality objectives. For medical students in higher vocational colleges, the particularly important goal of quality is medical ethics education. However, it is not difficult to find out that there still exists the phenomenon of favoring one or the other, attaching importance to professional knowledge, despising medical moral education, attaching importance to theoretical knowledge, and despising medical practice. This has an extremely adverse effect on the formation of medical ethics of medical students, and further hinders its development in the future. This requires higher vocational colleges to analyze the problems existing in the current education of students' quality education, and to develop new teaching model and methods path study, with a view to promoting the medical ethics of medical students in higher vocational colleges [1].

\section{Current Situation of Medical Ethics Education for Medical Major Students in Higher Vocational Colleges}

The relevant medical moral education courses offered by medical majors in higher vocational colleges in China mainly include: ideological and political courses, ethics and psychology, etc. From the perspective of the courses offered, the status of medical ethics education in higher vocational colleges and universities in China is considerable. Students also have some understanding of basic medical ethics, but in-depth research can find that there are some shortcomings in medical ethics education in colleges and universities.

\subsection{Pay Attention to Theory Education only in Teaching, Ignore Behavior Guidance}

Higher vocational colleges are the colleges which mainly cultivate professional and technical talents, and the public are often misled by this concept. It is believed that the teaching of higher vocational colleges should be based on the cultivation of students' professional skills and the knowledge of theory. Therefore, the higher technical level and weak basic knowledge of the students in higher vocational colleges have been caused. In the course of professional teaching, 
teachers pay more attention to the training of medical knowledge and medical skills in the course of teaching. It is also a symbolic teaching for medical ethics education, and does not guide students in behavior. The teaching methods have always been used in traditional teaching methods, and the theory of medical ethics education is divorced from strict stress. In addition, in the way of assessment, the school also often uses theoretical and skill assessment as a final goal to improve, and not the medical ethics expression and medical ethics behavior as a basis for assessment. In addition, higher vocational students are generally less aged, they can't deeply understand the hard work of medical practice, not aware of the sense of responsibility in the society as a doctor, and it is difficult to give the dedication as a contribution. The traditional medical ethics education lacks specific guidance, the content is lack of effectiveness and openness, it is difficult to let the students feel the specific concept of medical ethics, and can't know how to express their care for the patients through speech, and it is difficult to complete the integrity of medical ethics.

\subsection{The Teaching Staff is Single and Lacks the Perfect Educational Evaluation Mechanism.}

In analyzing the deficiency of medical ethics education in higher vocational colleges, we should first realize the problem of teachers. For vocational schools such as vocational colleges, the teachers of professional courses are strong, but for ideological and political, ethics, psychology, which can improve the medical ethics of medical students, can be said to be rare, very few. In order to maximize the medical knowledge learned by medical students, it is necessary to combine the knowledge of sociology, ethics, psychology and other disciplines to channel the professional knowledge to promote the students in the future job of humane rehabilitation treatment of patients. For general medical as far as higher vocational colleges are concerned, their medical teachers prefer to teach professional courses, and the moral courses of medical students are often assigned to public teachers, and the teachers of public courses are limited by the less time of the courses, which leads to their inability to complete the workload. As a result, students cannot really understand the moral to the depth. Therefore, teachers cannot meet the current needs of medical ethics education in higher vocational colleges no matter from the professional background or from the practical experience [2].

In addition, the imperfection of teaching evaluation mechanism is also an important reason for the lower level of medical ethics education in higher vocational colleges. At present, the main evaluation mechanism for teachers' teaching in medical higher vocational colleges is mainly presented in the form of score quantification. As a kind of imperceptible emotional education, medical moral education is supported by emotion and requires students to realize the process of hard to carry out quantitative assessment. The teaching of this course requires teachers to invest a great deal of time and energy in the classroom to help students truly understand the power of morality from the deep inside of their hearts. It is difficult to teach this kind of course. Through the traditional assessment, the medical higher vocational colleges should break the traditional teaching evaluation mechanism, bring forth the new from the old, improve the evaluation mechanism of the medical moral education constantly, thus promote the long-term development of the medical moral education in the higher vocational colleges.

\subsection{Medical Ethics Education Attaches Importance to Classroom Narration, Neglects Extracurricular Practice}

Various research materials show that the main way of medical ethics education for medical students in higher vocational colleges in our country is classroom teaching, at present. Teachers only need to go into designated classrooms on time to teach textbook knowledge to students only according to the course arrangement. The practice teaching in the school is mainly to practice the students' professional skills, so it is easy to cause the students to learn medical ethics and medical practice content out of touch. In addition, the students in higher vocational colleges can only passively accept the curriculum of medical ethics education because of their less disciplined and weak learning ability, and they lack the opportunity to practice in person, and it is difficult to translate the theory of medical ethics into practice in clinical practice. Lack of humanistic care for the patients, their own medical road in the future has a very poor impact. 


\section{Analysis of Medical Ethics Education for Medical Students in Higher Vocational Colleges}

In recent years, with the frequent occurrence of doctor-patient accidents, medical moral education has been paid more and more attention around the world. There are many factors affecting medical ethics (Fig. 1), and school education plays an important role in improving the personal quality of medical personnel.

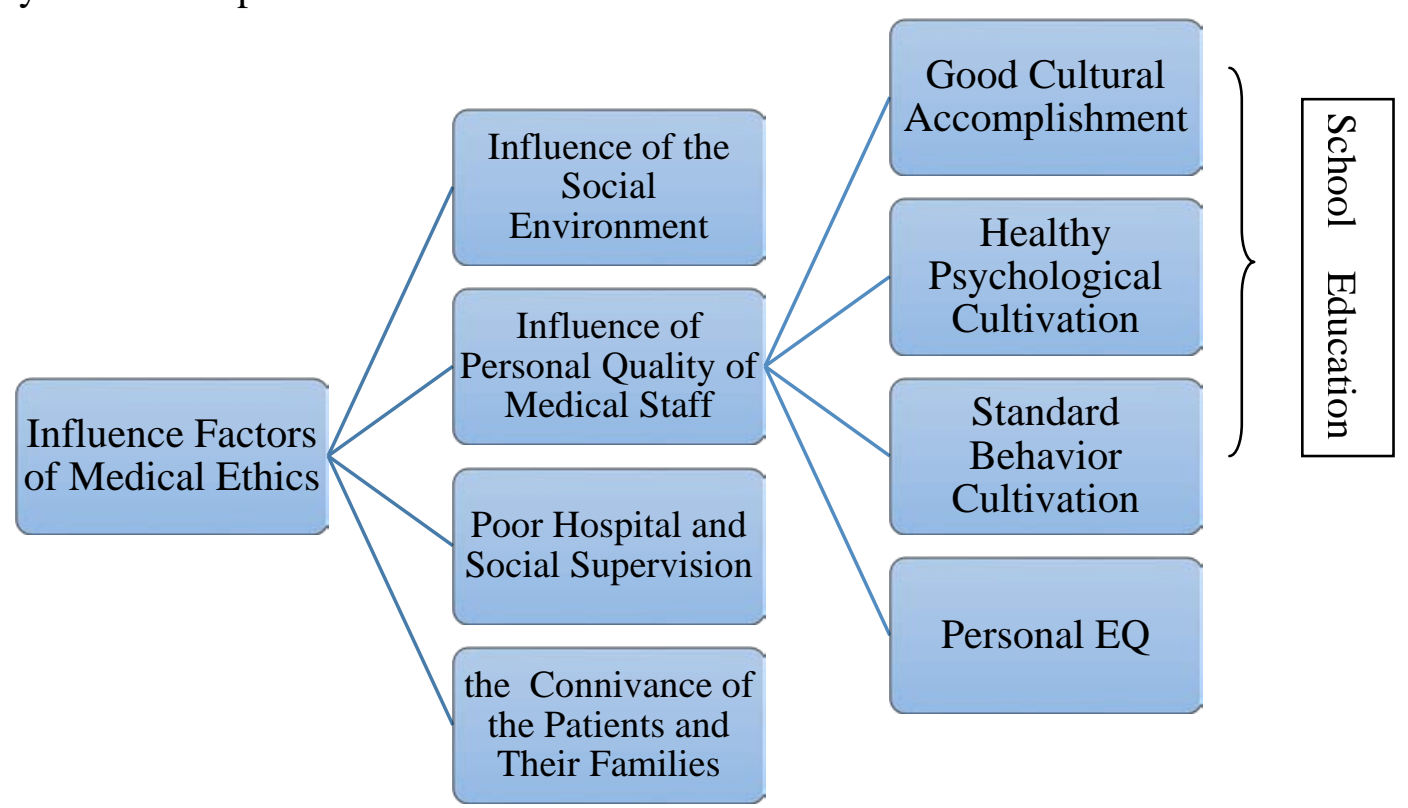

Fig. 1 Influence Factors of Medical Ethics

There are still many problems in the form of medical ethics education in higher vocational colleges in China, especially in the way of education. Therefore, in order to make up for the deficiency of medical ethics education in medical higher vocational colleges, we will explore the effective way and teaching mode suitable for the professional ethics training of medical students in the following aspects.

\subsection{Enrich the Means of Education and Teaching, and Create Multiple Ways and Methods of Teaching}

At present, the medical students in higher vocational colleges are mostly post-90s. They are active in thinking, easy to accept new things, and have strong curiosity about new things. From this point of view, the traditional way of medical ethics education is no longer suitable for the current structure of medical ethics education. The traditional medical ethics education is mainly based on theoretical lectures, and the class is boring, which is not attractive to students, which leads to poor teaching effect. This kind of teaching mode can only make students master the theory of "death" simply, but do not know much about the substantial connotation of medical ethics, so that students cannot correctly understand the value of medical ethics to society, themselves and patients, which leads to students' emotional indifference. Lack of the humanistic care of the patients easily leads to the contradiction between the doctor and the patient [3]. Therefore, it is necessary to explore the new model of medical ethics which is more suitable and more effective according to the characteristics of the students and the law of the development of the students' personality. Between the doctor and the patient, the medical ethics runs through the medical knowledge, which runs through the whole medical practice. On the basis of training the students' medical ethics effectively, the students' professional moral will is exercised, and the medical students' awareness of communication and communication ability are promoted [4].

\subsection{Strengthening the Teaching Staff Construction of Medical Ethics Education Course for Medical Students in Higher Vocational Colleges}

Teachers seriously affect the education and teaching level of the whole school. Therefore, in order to effectively improve the level of medical ethics education in medical higher vocational 
colleges, it is necessary not only to carry out curriculum reform, but also to build up the teaching staff, improve their teaching ability, strengthen self-cultivation. Medical ethics education usually consists of two aspects: love of profession and sympathy for patients. Only by devoting oneself to the boundless love of the profession, can we cherish the hard-won job opportunities. As a medical ethics teacher, we should first of all run this emotion through ourselves and express it sincerely through our own feelings. In addition, the teacher should also lead the students to comfort the patients, experience the patient's true feelings, and let students to improve their self-cultivation, improve medical ethics in the teacher's words and deeds constantly. In order to combine medical ethics education with professional education, it is very important to build a high level contingent of teachers [5].

Besides, the development course of medical ethics is set up to allow professional teachers and Humanities Teachers to communicate through the course, learn from each other's teaching methods, and constantly improve and choose better teaching methods to convey medical knowledge to students, so as to achieve the effective integration of knowledge goals, ability goals and quality goals, and work together to cultivate moral, knowledge-based and technical talents.

\section{Conclusion}

At present, with the rapid development of social economy and the continuous improvement of people's living standard, people begin to pay more and more attention to their own health, which puts forward higher requirements for medical education in the new period. The society pays more and more attention to medical ethics education. As far as higher vocational medical colleges are concerned, although they have made some progress in the teaching of medical technology, they have obviously not paid enough attention to the education of medical ethics, which makes it impossible for students to better apply medical knowledge to practice. Therefore, the article mainly discusses the problems in medical ethics education of medical students in higher vocational colleges, and puts forward some relevant countermeasures, hoping to provide effective help.

\section{Acknowledgements}

In this paper, the research was sponsored by the Vocational Teaching Reform of Shandong Province (Research and Practice of Nursing Core Competence Training System in Higher Vocational Colleges, Project No. 2017217).

\section{References}

[1] Hui Cheng. A study on the methods and paths of Professional Ethics Education for Medical students in higher Vocational Colleges[D]. Southeast University, 2016.

[2] Ying Yang. A survey of the present situation of medical ethics education in high vocational college nursing students and the research on countermeasures. Zhengzhou University, 2013.

[3] Yan Qin, Yi Peng, Hongsheng Wang. Investigation on the status quo and Countermeasures of Medical Ethics cultivation among Medical students: a case study of Chongqing City Medical higher Vocational College [J]. Chinese and foreign entrepreneurs (27): 156-157.

[4] Yan Qin. Investigation and Analysis on responsibility consciousness of Medical students in higher Vocational Colleges: a case study of Chongqing City Medical higher Vocational College [J]. Learn theory, 2015 (23): 125-126.

[5] Huang Siyu. Present situation and Countermeasures of Humanities Education in Medical higher Vocational Colleges [D]. Suzhou University, 2010. 